\title{
Модификация методов оценки эколого-экономического ущерба лесным экосистемам при массовом размножении насекомых
}

\author{
КУЛАКОВА Н.Н., МЕЛЬНИЧЕНКО Н.П. СУЛЬТСОН С.М.
}

Сибирский государственный университет науки и технологий имени академика М.Ф. Решетнева, 660037, г. Красноярск, проспект им. газеты Красноярский рабочий, 31

\begin{abstract}
Ключевые слова: полиграф уссурийский, пихта сибирская, лесные ресурсы, экологический ущерб, экономический ущерб
\end{abstract}

Лесные пожары, насекомые и болезнинаносят значительный экологоэкономический ущерб во всех регионах России. Ежегодно в лесных экосистемах встречаются насекомые-вредители, массовое размножение которых приводят к снижению продуктивности лесных экосистем. Развитие возбудителей болезней также может приводить к нежелательным последствиям в биогеоценозах.

Эколого-экономический ущерб лесопользованию от неблагоприятных факторов природного и антропогенного характера включает в себя суммарные фактические и потенциальные потери лесных ресурсов и экологических функций леса, выраженные в стоимостной форме (Мельник, 2018).

Первые работы по проблемам расчета экономического ущерба от загрязнения окружающей среды появились в советской экономической литературе в середине 70-х гг. В.Т.Халдеев один из первых предложил понимать под ущербом дополнительные затраты, необходимые для ликвидации негативных социально-экономических последствий загрязнения воздушного бассейна, выраженных в стоимостной форме. Данное определение не разъясняет основных категорий ущерба, а носит общий характер(Путинцева, 2014).

Основополагающей в этой сфере является работа экономиста Т.С. Хачатурова, в которой рассматриваются народнохозяйственные проблемы с учетом охраны природы, в частности, проблемы комплексного планирования использования природных ресурсов. В своих работах Т.С. Хачатуров писал: «Под экономическим ущербом понимается исчисляемый в стоимостных единицах ущерб, причиняемый возобновимым и невозобновимым ресурсам. Социальным ущербом является тот, который наносится здоровью и условиям благополучия и существования людей» (Козлова,2003).

Расчет эколого-экономического ущерба в сфере природопользования представляет собой наиболее сложную и актуальную задачу. Существуют различные методики определения эколого-экономического ущерба, в которых излагается порядок учета потерь, возникающих в связи с загрязнением окружающей среды, способы их расчета, приводятся некоторые 
методы выявления зависимости между степенью загрязнения окружающей среды и величиной ущерба и т.п.

Предлагались самые различные методологические подходы. Так, методика определения ущерба от загрязнения атмосферы, разработанная в Сумском филиале Харьковского политехнического института, предполагала расчет по трем компонентам: пыли, сернистому ангидриду и окисям углерода. В ее основу было положено понятие удельного ущерба, причиняемого единицей выбросов (на 1 тыс. человек, 1 га сельхозугодий и т.Д.).

Московскими инженерно-экономическими научно-исследовательскими лабораториями (МЭНИЛ) Минводхоза СССР были разработаны «Рекомендации для определения ущерба от загрязнения водных источников» (утверждены приказом № 191 Минводхоза СССР от 4 апреля 1975 г.). Документ содержал единую для всех отраслей народного хозяйства методику определения потерь от загрязнения водных источников. В ее основу была положена затратная концепция - ущерб определялся через объем затрат, необходимых для восстановления потерь, нанесенных загрязнением.

В это же время ВНИИ ВОДГЕО предложил «Методику расчета экономической эффективности мероприятий по борьбе с загрязнениями водных источников». В ней рассматривались основные принципы экономического обоснования затрат на инженерные мероприятия по борьбе с загрязнением водных источников; при этом, естественно, предполагалось определение экономического ущерба от загрязнения.

В 1983 г. была разработана «Временная типовая методика определения экономической эффективности осуществления природоохранных мероприятий и оценки экономического ущерба, причиняемого народному хозяйству загрязнением окружающей среды» (одобрена постановлением Госплана СССР, Госстроя СССР и Президиума Академии наук СССР от 21 октября 1983 г. № 254/284/134). В данном документе отражены ранее разработанные методы оценки ущерба воздушной среде и водным источникам и добавлены методические положения, охватывающие другие виды возможного ущерба.

Новый подход к оценке инвестиций потребовал внесения определенных корректировок и в методы определения ущерба от загрязнения окружающей среды. Многие авторы отмечают, что при расчете ущерба могут применяться как затратный, так и доходный методы.

В 1999 г. Госкомэкологией были утверждены «Методические указания по оценке и возмещению вреда, нанесенного окружающей природной среде в результате экологических правонарушений». В них содержатся рекомендации по оценке такого вреда,порядку организации и проведения работ территориальными органами Госкомэкологии России по расчету и обоснованию размеров убытков, а также порядку предъявления исков об их возмещении.В том же 1999 г. Государственным Комитетом РФ по охране окружающей среды была утверждена Временная методика определения предотвращенного экологического ущерба (Методика..., 1999). 
Все виды прямых и косвенных потерь полезных материалов являются, в конечном счете, потерями природных ресурсов, так как их приходится компенсировать дополнительной добычей первичного природного сырья. Прямой потерей является уничтожение леса от пожаров, порубок, загрязнения воздуха, от размножения вредных насекомых (гусениц и др.). Непосредственный ущерб наносится обитателям водоемов - рек, озер, морей, океана.

Учитывая специфику лесной отрасли, Е.П. Чепуровым (2015) предлагается следующая структура (рисунок 1):

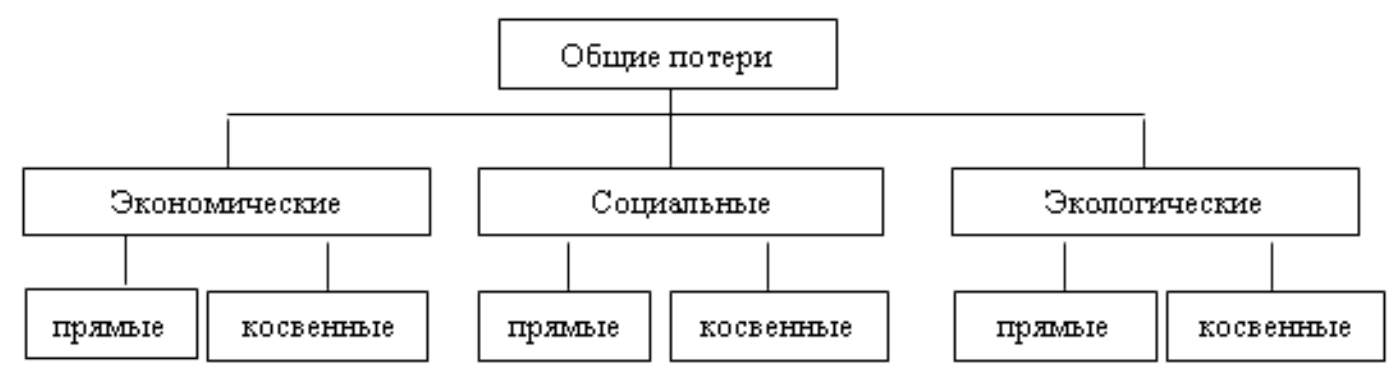

Рисунок 1 - Структура потерь в системе лесопользования

Под прямыми потерями в результате управления и пользования лесными ресурсами понимаются потери и убытки всех структур национальной экономики, государства как собственника ресурсов, оцененных лесных ресурсов (с учетом их эколого-экономической и социальной значимости) и убытков, вызванных этими потерями, а также затраты, связанные с ограничениями в развитии и восстановлением лесов.

Косвенные потери - ущербы, убытки и дополнительные затраты, которые понесут собственники, потребители, пользователи и экосистема, непосредственно связанные с прямыми потерями.

Прямые и косвенные потери, в совокупности, образуют общие (комплексные) потери или общий ущерб (Рязанов,2011; Чепуров,2015).

Эколого-экономическая оценка ущерба окружающей природной среде заключается в определении фактических и возможных (предотвращаемых) материальных и финансовых потерь и убытков от изменения (ухудшения в результате антропогенного воздействия или улучшения в результате проведения природоохранных мероприятий) качественных и количественных параметров окружающей природной среды в целом и ее отдельных экологоресурсных компонентов (Животягина, 2015).

В последнее десятилетие список вредителей леса России пополнил уссурийский (пихтовый) полиграф (Polygraph usproximus Blandf.), короед дальневосточного происхождения, который сформировал устойчивые самовоспроизводящиеся популяции за пределами исторического ареала и нанес существенный вред пихте сибирской Abies sibirica Led. и темнохвойным экосистемам в целом. Предварительная оценка возможного ущерба российскому лесному хозяйству от уссурийского полиграфа из-за потери 
древесины была предпринята Ю.И. Гниненко и М.С. Клюкиным(2011): результаты оценки показали высокую вероятность проникновения вредителя в новые регионы, а также высокую вероятность его акклиматизации на новых территориях и высокий уровень потенциальной экономической вредоносности $(П Э В=7,18)$. Итоговая оценка потенциального ущерба более чем в 2 раза выше пограничного показателя, равного 1,25.

Для пихтачей юга Томской области была разработана методикаоценкиущербаотуссурийскогополиграфа, которая включает в себя основные элементы теоретических и методическихразработок в области экономики лесопользования. По предварительным расчетам величина прямого ущерба в очагах составила 44 млн руб., а косвенного 48,14 млн руб. (Мельник,2018).

Также была предложена укрупненная оценка стоимости экосистемных услуг леса, удобная с точки зрения расчета суммарного возможного ущерба от потери экосистемных услуг леса. В основу модели положен ущербот потери наиболее востребованной, вовлеченной в рыночный оборот, экономически отработанной и наиболее уверенно рассчитываемой услуги предоставление древесины. Полученный результат превышает имеющиеся оценочные значения: стоимость лесных ресурсов Калужской области соответствует оценке запасов древесины на корню (попенная плата), что составляет примерно 60\% всей стоимости лесного комплекса, остальные $40 \%$ приходятся на важнейшие экосистемные функции леса (Логинов,2018).

Некоторые исследователи в качестве основы для расчета использовали Руководство по локализации и ликвидации очагов вредных организмов, утвержденное приказом Рослесхоза от 29.12.2007 № 523 (Животягина, 2015).

Для определения ущерба, нанесенного животному миру, также применяется Методика исчисления размера вреда, причиненного объектам животного мира, занесенным в Красную книгу Российской Федерации, а также иным объектам животного мира, не относящимся к объектам охоты и рыболовства и среде их обитания (Приказ, 2008).

Кроме этого для определения ущерба биоресурсам можно использовать нормативы допустимого изъятия охотничьих ресурсов и нормативы численности охотничьих ресурсов в охотничьих угодьях (Приказ, 2010).

Расчет локального эколого-экономического ущерба позволит организовать рациональное природопользование и обосновать создание особо охраняемых природных территорий в регионах.Оценка экономического и экологического ущерба лесам позволит оценить не только фактически понесенный ущерб, но и потенциальные риски лесному хозяйству.

Для России экономические потери лесным экосистемам практически не определены из-за отсутствия разработанных методик для специфических условий российского лесного хозяйства и сложности прямого переноса зарубежного опыта (Мельник,2018).Стоимостная оценка ущерба, нанесенного лесным экосистемам, представляет особый интерес для лесопользователей всего мира. Более половины (54\%) мировых запасов леса 
сосредоточены в пяти странах: Российская Федерация (20\%), Бразилия (12\%), Канада (9\%), США (8\%) и Китай (5\%) (FAO, 2020). В рамках данной работы авторы рассматривают мировой опыт расчета экономического и экологического ущерба лесным экосистемах на примере пяти «лесных держав».

В настоящее время, оценка экономического ущерба сводится в большинстве случаев к подсчёту стоимости отдельных компонентов лесной экосистемы. Причем, оценке поддаются, как правило, те элементы, которые обладают рыночно ценностью: древесина, недревесные лесные ресурсы, охотничье-промысловые ресурсы, прибыль от осуществления рекреационной деятельности и выдачи разрешений на добычу охотничьих ресурсов, а также стоимость вложений в лесной участок (машины, оборудование, удобрение, пестициды и т.д.) (HaigenXuet al., 2006). Данный тип оценки экономического ущерба является регрессивным, то есть оцениваются фактически понесенные потери. Современное лесное хозяйство стремится найти способ оценить потенциальный экономический и экологический ущерб, для чего необходимо провести полноценную оценку лесов. Более того, для качественной оценки стоимости лесной экосистемы, необходимо также оценить свойства леса (водоохранные, климаторегулирующие, противоэрозионные, оздоровительные и пр.) и экосистемные услуги.

Для оценки потенциального экономического ущерба от нарушения определенной территории необходимо оценить её стоимость. Точно оценить стоимость лесной экосистемы практически невозможно, однако даже попытка произвести хотя бы приближенную стоимостную оценку обладает огромной ценностью для оптимизации процесса принятия решений в сфере лесоуправления.

Концепт общей экономической ценности участка позволяет наиболее полно провести стоимостную оценку определенного участка лесопокрытой территории. Общая экономическая ценность участка складывается из следующих элементов: непосредственная прибыль, косвенная ценность, страховая стоимость, субъективная ценность (Lykke E. Andersen, 2015). Например, непосредственная прибыль от лесного насаждения представляет собой реальную стоимость древесины и недревесных ресурсов, а также доходы от туристической активности на данном участке и генетического материала, произрастающего там. Косвенная ценность относится к экологическим функциям, осуществляемым лесными экосистемами: почвозащитная и водоохранная функции, защита биоразнообразия, углерододепонирующая функция и т.д. Страховая стоимость - стоимость, которую люди готовы были бы заплатить для того, чтобы сохранить данный участок леса для использования его ресурсов в будущем. Субъективная ценность - стоимость, которую люди готовы заплатить только за то, чтобы сохранить определенную экосистему, даже без возможности пользоваться её ресурсами (в том числе рекреационными).

Особое внимание также уделяется стоимостной оценке экосистемных функций лесных экосистем. Смысл подобной оценки заключается в том, 
чтобы определить ценовое значение экосистемных функций, осуществляемых конкретным лесным участком. Соответственно, в случае нарушений, препятствующих выполнению данных функций (например, нашествие насекомых-вредителей), возможно будет оценить нанесенный ущерб. К сожалению, экосистемные услуги не поддаются рыночной оценке, поэтому определить их стоимость возможно исключительно субъективно. А именно, стоимость каждой экосистемной функции определяется ценой, которые люди готовы заплатить за поддержание её осуществления. Для проведения некоторый исследований (Seth Binderetal., 2017), например, создаются специальные гипотетические рынки. Подобные рынки позволяют оценить желание людей платить за доступ или же просто существование определенной экосистемной услуги, а также их готовность получить некоторую компенсацию за прекращение осуществления данной функции. На основе предпочтений и компромиссов, принимаемых людьми на данных рынках, исследователи могут присвоить определенную стоимость конкретной экосистемной услуге. Участие в подобной оценке может быть предоставлено как людям принимающим решения в сфере лесопользования, так и простым обывателям в зависимости от цели исследования (G.G.Brown,2009)

Таким образом, точному подсчету поддается только стоимость древесины, недревесных лесных ресурсов, потери дохода от туризма и другие элементы лесной экосистемы, обладающие рыночной ценностью. Стоимостная оценка экологических функций, осуществляемых лесными экосистемами, возможна исключительно субъективно. Она сводится к необходимости определения цены, которую люди готовы заплатить за то, чтобы экосистема продолжала выполнять эти функции. Для определения подобной ценности можно представить потенциальный ущерб в случае если данный лес будет уничтожен. Оценка подобного рода неизбежно основывается на предположениях и допущениях и не может быть абсолютно достоверной. Разработка методики стоимостной оценки экологических функций лесных экосистем, несомненно, требует разработки. Тем не менее, попытка оценки, хоть и приблизительная, даст возможность ранжировать территории по их условной ценности, что позволит в свою очередь более оперативно и адекватно принимать решения в сфере лесоуправления и лесопользования.

Работа выполнена в рамках государственного задания Минобрнауки России на выполнение коллективом научной лаборатории «Защита леса» проекта «Фундаментальные основы защиты лесов от энтомо- и фитовредителей в Сибири» (№ FEFE-2020-0014)

Библиографический список

1. Приказ«Об утверждении нормативов допустимого изъятия охотничьих ресурсов и нормативов численностиохотничьих ресурсов в охотничьих угодьях» от 30 апреля 2010 г. N 138 
2. Приказ МПР России "Об утверждении Методики исчисления размера вреда, причиненного объектам животного мира, занесенным в Красную книгу Российской Федерации, а также иным объектам животного мира, не относящимся к объектам охоты и рыболовства и среде их обитания" от 28.04.2008 N 107 (ред. от 12.12.2012)

3. Государственный комитет Российской Федерации по охране окружающей среды.Методика определения предотвращенного экологического ущерба. - М.: 1999. 72 с.

4. Гниненко, Ю.И., Клюкин М.С. Уссурийский короед на территории России / Ю.И. Гниненко, М.С. Клюкин // Защита и карантин растений,№11. 2011. С. 32-34.

5. Животягина, Н.И., Орехова, Н.В., Казанцева, Н.В. Применение расчета эколого-экономического ущерба в лесопользовании / Н.И. Животягина, Н.В. Орехова, Н.В. Казанцева // Политематический сетевой электронный научный журнал Кубанского государственного аграрного университета, № 88.2013.С. 744-754.

6. Козлова Н.И. Эколого-экономический ущерб при загрязнении окружающей среды: Учебное пособие. - Курган: Изд-во Курганского гос. унта, 2003. - 134 с.

7. Логинов, А.А., Лыков, И.Н., \& Васильева, М.А. Укрупненная оценка стоимости экосистемных услуг леса./ А.А. Логинов, И.Н.Лыков, М.А. Васильева, // Проблемы региональной экологии, 3. 2018.С. 120-124.

8. Мельник, М.А. Оценка эколого-экономического ущерба лесопользованию,вызванного инвазией уссурийского полиграфа в темнохвойные экосистемы Сибири. / М.А. Мельник, Е.С. Волкова, Э.М. Бисирова, С.А. Кривец // Известия Санкт-Петербургской лесотехнической академии, № 225, 2018. С. 58-75

9. Путинцева, Н.Н. Подходы к оценке экономического ущерба в современных условиях./Н.Н. Путинцева // Интерэкспо ГЕО-Сибирь, Вып.6. №1, 2014. C.161-165.

10. Резанов, В. К. Несоответствия развития лесного комплекса принципам устойчивого развития и общая схема их экономической оценки / В. К. Резанов, Е. П. Чепуров // Современные механизмы реализации управленческих функций: сб. науч. тр. Вып. 3. - Хабаровск : Изд-во ДВГУПС, 2011.

11. Ховавко, И.Ю. Экономический ущерб от загрязнения как форма оценки внешних эффектов/ И.Ю. Ховавко //Вестник Ставропольского государственного университета, №4,2011.С.291-295.

12. Чепуров Е.П. Системный подход к оценке устойчивого, сбалансированного развития лесного комплекса региона//Власть и управление на Востоке России. 2015. № 1 (70). С. 52-59.

13. FAO. 2020. Global Forest Resources Assessment 2020: Main report. Rome. URL: https://doi.org/10.4060/ca9825en; 
14. Assessment and Valuation of Forest Ecosystem Services: State of the Science Review(2017) Seth Binder, Robert G. Haight, Stephen Polasky, Travis Warziniack, Miranda H. Mockrin, Robert L. Deal, and Greg Arthaud

15. Brown, G.G.; Reed, P. 2009. Public participation GIS: A new method for use in National Forest planning. Forest Science. 55(2): 166-182., Brown, G.; Donovan, S. 2014. Measuring change in place values for environmental and natural resource planning using public participation GIS (PPGIS): results and challenges for longitudinal research. Society and Natural Resources. 27:36-54

16. Lykke E. Andersen, 2015. "A Cost-benefit Analysis of Deforestation in the Brazilian Amazon," Discussion Papers 0065, Instituto de Pesquisa Econômica Aplicada - IPEA. URL: http://www.ipea.gov.br; Xu, Haigen\& Ding, Hui \& Li, Mingyan \& Qiang, Sheng \& Guo, Jianying \& Han, Zhengmin \& Huang, Zongguo \& Sun, Hongying \& He, Shunping \& Wu, Hairong \& Wan, Fanghao. (2006). The distribution and economic losses of alien species invasion to China. Biological Invasions. 8. 1495-1500. 10.1007/s10530-005-5841-2. 